\title{
Erosion of the thermocline in the Gulf of Patras, due to a severe wind event
}

\author{
Fourniotis N.Th..$^{1,2, *}$ \\ ${ }^{1}$ Department of Civil Engineering, Technological Educational Institute of Western Greece, Megalou Alexandrou 1, GR-263 34 Patras, \\ Greece \\ 2Department of Civil Engineering, University of Patras, University Campus, GR-26 500, Greece \\ Received: 11/05/2017, Accepted: 25/08/2017, Available online: 26/01/2018 \\ *to whom all correspondence should be addressed: e-mail: nfou@upatras.gr
}

\begin{abstract}
Three-dimensional numerical simulations, performed using the MIKE 3 FM (HD) code, have been used to study the effect of a severe wind event on the early stratification structure in the Gulf of Patras, Greece. Before the onset of the severe wind event thermocline was at an approximately mean depth of $\sim 10 \mathrm{~m}$. The wind action deepened the well mixed layer of the epilimnion at the surface and redistributed the thermal stratification to a new stable formation where tilt and erosion of the thermocline occurred. Under the effect of wind, the thermocline was established in a new mean depth of $\sim 60$ $m$. Furthermore, strong wind - generated internal waves, in the area of Rio-Antirio straits, were found to affect the exchange flowrate at the straits. Comparison of the exchange flowrate between the barotropic and the baroclinic flow, under the same severe wind conditions, revealed a deviation of approximately $20 \%$ of the resulting flowrate, under steady wind conditions. The hydrodynamic response of the Gulf, under these wind conditions, i.e., wind-induced currents, turbulence structure in the water column, internal waves and flow patterns, has been simulated indicating basic, unique, flow characteristics for the baroclinic flow in contrast with the barotropic ones.
\end{abstract}

Keywords: thermocline, stratification, Gulf of Patras, MIKE 3 FM (HD), wind-induced flow, hydrodynamic circulation

\section{Introduction}

The Gulf of Patras (referred, hereafter, as "Gulf") is located in Western Greece, centered at $38^{\circ}$ latitude, which corresponds to a UTM-34 zone. It is one of the largest flowthrough embayments in Greece being about 40-50 km long, $10-20 \mathrm{~km}$ wide, and with an area of $535 \mathrm{~km}^{2}$. The maximum depth of the Gulf is $138 \mathrm{~m}$, while the mean depth was calculated to be approximately to $56 \mathrm{~m}$ (Fourniotis, 2009). On the SE coast of the Gulf lies the port of the city of Patras, while at the NW coast a $12 \mathrm{~km}$ long sand bar is formed, which separates the Messolonghi lagoon with Gulf's open waters. The lagoon constitutes the largest wetland in Greece and one of the largest and most important in
Europe, both in ecological and in economic terms (e.g. Cataudella et al., 2015).

The need to understand the physical oceanography and the hydrodynamic behavior as well as to manage the quality of Gulf's waters, has led to continuing efforts of simulating the circulation of the Gulf (Fourniotis and Horsch, 2010; 2015; Horsch and Fourniotis, 2017). Further, environmental studies of pollution scenarios, covering the far field dilution of effluents into the Gulf released from the Waste Water Treatment Plant of the city of Patras, as well as the effect of Glafkos River on the quality of coastal waters (Fourniotis and Horsch, 2012; 2013) has responded in crucial questions concerning the coastal water management. In these previous studies the effect of wind, tides and thermal stratification on flow hydrodynamics have been extensively studied shedding light in characteristic flow regimes and resulting flow structures of barotropic and baroclinic circulation, which arises in the Gulf's waters. Moreover, salient features of the Gulf's hydrodynamics, i.e. a central cyclonic gyre, internal waves at the Rio-Antirio straits, upwellings on specific sites and flow structure, observed and/or recorded in the past by other researchers (e.g. Papailiou, 1982; Lascaratos et al., 1989; Hadjitheodorou et al., 1992;) have been explained and the exact conditions under which they occurred have been identified.

In spite of the fact that crucial flow characteristics were revealed via these three-dimensional simulations, it is noteworthy that these simulations were conducted: (a) mainly for the prevailing, moderate winds affecting the Gulf, i.e., SW and NE with a mean value of $6 \mathrm{~m} / \mathrm{s}$, (b) for short periods where the structure of the stratification was considered to remain essentially stable and uniform in the water body resulting to a baroclinic flow.

In this work the effect of a severe wind event on the deepening and erosion of the early summer thermocline is studied via three dimensional simulations. Our aim is to elucidate the role of the wind on stratification's destruction, as well as the time scale of the phenomenon. For better understanding - keeping in mind the short period of simulation which is restricted at the level of $\sim 4$ days the present study is limited to the case of no surface heat 
flux. Moreover, the effect of tides is ignored, i.e. we consider that the wind acts during the neap tides, since in a first stage we anticipate exclusively the role of the wind on thermocline's deepening and erosion.

\section{Materials and methods}

\subsection{Stratification in the Gulf of Patras}

\subsubsection{Available field measurements - summer regime}

In this section, characteristic and prominent works that shed light on understanding of the hydrodynamic behavior and the physical oceanography of the Gulf are briefly summarized. These works are based on field measurements or observations during the summer regime, which are pertinent here. Papailiou, (1982), study was designed to give a comprehensive view of the annual evolution of stratification (i.e. temperature and salinity measurements), the development of currents and the propagation of tides at the entire body of the Gulf. The field data were collected during four periods covering the winter and summer circulation regime of the Gulf: i.e., August 1981, November 1981, March 1982 and June - July 1982. The study of Friligos et al., (1985) reports measurements, taken at a large number of stations that cover the entire range of the Gulf, during the summer. Based on in situ measurements of temperature, salinity, dissolved oxygen and nutrients during August 1980, important results were concluded. Papageorgiou et al., (1987) collected current data in the Gulf of Patras during summer (August) 1980. The researchers concluded that current speeds are generally weak apart from the area of Rio-Antirio, where the currents found to be high. Moreover, basic characteristics of the circulation pattern, as well as the effect of tides and the morphology of the area on the water flow were revealed. Lascaratos et al., (1989) analyzed a large number of satellite infrared images, taken during the months from June 1981 to November 1981, over the gulfs of Patras, Nafpaktos and Corinth, giving a description of sea surface temperature features and their evolution in time, during the summer regime. The satellite data were interpreted using theories of wind induced upwellings near capes. A more local study conducted by Antonopoulos et al., (1992) and Hadjitheodorou et al., (1992) across the RioAntirio straits, during three different periods from August 1991 to April 1992, at the eastern end of the Gulf, before the construction of the Rio-Antirio bridge. The objective of these measurements was to analyze the local dynamics of water surface elevation, currents, density, salinity and temperature fields, taking into consideration the forcing provided by tidal and wind action.

\subsubsection{Early summer stratification in the Gulf}

Based on field measurements found in Papailiou, (1982) study, it is shown that the Gulf presents an annual cycle of stratification. Specifically, during the summer months a warm surface layer, the epilimnion, floats on the colder deeper part of the Gulf, the hypolimnion. Underneath the epilimnion and above the hypolimnion, a sharp temperature transition is formatted, which is termed thermocline. This three-layer structure seems to remain nearly stable for the summer period (i.e. from the early June to the end of October). During the fall and early winter the surface layer gradually cools. The winter months are followed by a general overturning of the Gulf's waters, as has been observed in lakes and reservoirs (e.g. Fischer et al., 1979) where well mixed conditions occur in the water column. Based on Papailiou, (1982) study these well mixed conditions are completed by the end of March. During this period the Gulf remains homogeneous, and the flow is considered to be barotropic. The strength of the local winds is also important to the stratification formation, especially for stationary winds blowing for hours or permanent direction.

The simulations presented below are based on early summer stratification regime. For this purpose measurements for the thermal stratification collected during June 1982 and reported in Papailiou, (1982) study, were utilized. Based on these vertical temperature profiles it is concluded that during June 1982 the Gulf of Patras was found to be well and uniformly stratified throughout its entire body (i.e. the stratification was considered to be one dimensional). This uniform and stable stratification reasonably constitutes the first step on the simulation of the baroclinic circulation in the Gulf. It is worth noting, however, that as reported by Papailiou, (1982), the stratification in the Gulf is altered during August. Considering the field measurements, the Gulf can be divided into two sub regions: the southern and northern, where different stratification structure occurred in the water column. These different structures lead to density variation in the horizontal plane which generates density currents. The hydrodynamic regime in the Gulf is expected to be affected by these flow structures.

Based on the vertical temperature and salinity profiles, found in Papailiou, (1982) study basic characteristics of the early summer stratification are concluded (i.e. June 1982). In early summer a permanent thermocline is established, limiting deep mixing of the winter. The nearly horizontal isotherms demonstrate the strong degree of temperature stratification induced by the solar radiation. Quite apart from the density stratification, formatted exclusively due to the thermal structure of the water column, the water at depths greater than $60 \mathrm{~m}$ was always remain colder than that at the surface. Specifically, the values of temperature found to be at least 7-9 grades lower than that at the well mixed layer of the epilimnion. The moderate to slight seasonality in the wider region of the Gulf, as well as the effect of the frequent, yet moderate summer winds, cannot generate enough mixing to break down the permanent thermocline - noting however, the slight shoaling of the thermocline at the coastal zone, where the depths are quite shallow. In these areas even moderate winds, blowing for hours affect the water column leading to erosion and destruction of the thermal stratification.

At this point it has to be noted that measurements used in the present study were conducted 35 years ago (Papailiou, 1982) and the effect of climate change on the stratification structure is not taken into account. As a general trend, climate change leads to global temperature rise. It is 
estimated that the mean temperature of the earth's surface will increase by the as much as $6{ }^{\circ} \mathrm{C}$ by the end of the twenty-first century (Bates et al., 2008, as referred by Modiri-Gharehveran et al., 2014). The global warming has a crucial impact on water bodies, affecting the thermal stratification. Under these conditions, the measured temperature stratification in the Gulf (Papailiou, 1982) is expected to have been affected or have slightly been altered, during the last 35 years. Recent studies (e.g. Coma et al., 2009; Modiri-Gharehveran et al., 2014) present the effect of climate change and global warming on stratification structure. Based on the above mentioned it is concluded that (a) an increase in air temperature leads to an increase in water body's temperature significantly affecting the thermal stratification, (b) the onset time of thermal stratification is earlier and it is more stable in the water column than that for the base year, (c) the thermal gradient in thermocline increases and gradually become sharper, because the increase in epilimnion temperature is greater than that of the hypolimnion temperature, (d) under continuous warming the stratification duration increases.

Therefore, the June stratification is expected to be slightly altered. Since these measurements have not recently repeated for the Gulf, we merely present a simulation of the expected circulation, as well as the erosion and deepening of the thermocline due to a severe wind event, anticipating the effect of the wind on stable early summer stratification. It is considered that no crucial deviations of the basic hydrodynamic characteristics and of the time scale of thermocline deepening and erosion could occur due to the climate change effect.

\subsection{The modeling method}

\subsubsection{The hydrodynamic code}

The simulations presented herein have been performed using the commercially available computational hydrodynamics code MIKE 3 Flow Model FM (where FM stands for flexible mesh). This modeling system, developed at the Danish Hydraulic Institute (DHI) for oceanographic, coastal and estuarine environmental applications (e.g. Fourniotis and Horsch, 2010; 2015), is based on a finite volume, unstructured mesh approach. The Hydrodynamic Module (HD) extracts numerical solutions from the threedimensional continuity, momentum, temperature, salinity, and density equations. The momentum equations are used in the incompressible, Reynolds averaged form of the Navier-Stokes equations (RANS), invoking the Boussinesq assumption and the hypothesis of hydrostatic pressure in the vertical.

The spatial discretization of the primitive equations is performed using a cell-centered finite volume method. In the horizontal plane an unstructured grid is used while in the vertical direction the discretization is structured. The elements are prisms or bricks whose horizontal faces are triangles or quadrilateral elements, respectively. A Riemann solver is used for computation of the convective fluxes, which makes it possible to handle discontinuous solutions. For the time integration a semi-implicit approach is used, where the horizontal terms are treated explicitly and the vertical terms implicitly (DHI, 2007).

The turbulence closure is achieved using the Smagorinsky formulation for diffusion in the horizontal and the standard $k-\varepsilon$ model in the vertical direction. The logarithmic wall functions are used for the boundary conditions. For the computations of the temperature/salinity fluxes a constant Prandtl/Scmidt number is assumed. To account for the Coriolis force a variable Coriolis parameter $f$ has been used. The free surface is taken into account using a sigmacoordinate transformation.

\subsubsection{Model validation}

In this section, details concerning the calibration and validation of the numerical model are provided. Because the main work of the hydrodynamic circulation in the Gulf is based on an existing model (Fourniotis and Horsch, 2010; 2015, Horsch and Fourniotis, 2017), we briefly summarize below the main validation tests, which have been already published.

Two bench-mark tests in idealized geometries have been examined. The first is simulation of the three-dimensional, wind-induced flow in a rectangular closed basin and comparison with existing experimental data. The second test concerned the numerical simulation of the threedimensional, unsteady, turbulent flow which develops in an open channel of mild slope. The numerically predicted results, for both problems, were found to converge towards the expected experimental and exact solutions, respectively (Fourniotis and Horsch, 2007).

Further, during the simulation of the barotropic and baroclinic circulation in the Gulf, the model was validated against field measurements. Basic hydrodynamic parameters which were satisfactorily reproduced by the model include: (1) the free surface water level distribution at characteristic sites of the Gulf, i.e. the port of the city of Patras and the Rio-Antirio Straits as a result of the tidal propagation in the whole basin, (2) currents' velocity at the straits of Rio-Antirio, (3) the surface temperature field in the Gulf, under the effect of characteristic winds and (4) upwelling incidents in specific sites in the Gulf.

\subsubsection{Computational domain and grid}

The numerical representation of the coastline and the bathymetry of the Gulf of Patras were based on digital maps of the Greek Hydrographic Service of the Hellenic Navy. From these maps, ASCII files, required for the mesh generation of the hydrodynamic code, were produced using a GIS module, which was also used to convert the digital data to the appropriate UTM-34 zone projection.

The numerical domain was defined to include parts of the adjacent seas, since the exchange flows between the Gulf of Patras and the Gulf of Corinth on the one end and the Ionian Sea on the other, are among the hydrodynamic quantities of interest. The numerical grid, used for the simulations reported below, was identical to that used for simulation of the barotropic wind-induced circulation in the same gulf (Fourniotis and Horsch, 2010), where numerical experiments for testing the adequacy of the 
numerical domain were also discussed, and will not be repeated here. The resolution of the horizontal unstructured as well as the vertical structured grid is shown in Fig. 1. In the horizontal plane a non-uniform computational mesh was generated, where the resolution was made finer close to the coasts and the grid size

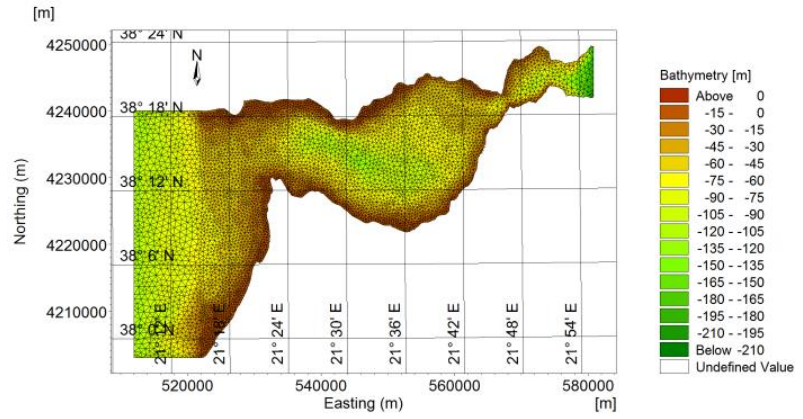

(a) increased gradually up to $1000 \mathrm{~m}$ in the offshore region of the Gulf. In the vertical plane 15 layers over depth have been used. A time step as small as $4 \mathrm{~s}$ was required to satisfy the Courant-Friedrichs-Lewis (CFL) criterion and avoid divergence.

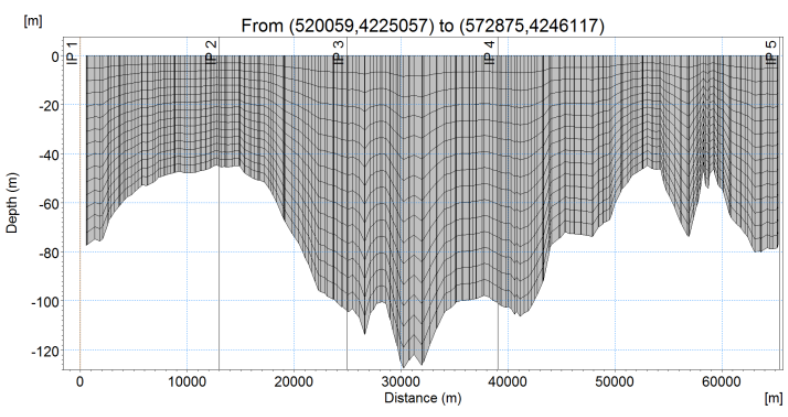

(b)

Figure 1. (a) Bathymetric map of the Gulf of Patras, with isobaths shown every $15 \mathrm{~m}$. Superimposed is the unstructured triangular mesh. Axis annotation in Easting and Northing is displayed in meters; superimposed on the map is the geographical net of longitude $(E)$ and latitude $(N)$. The co-ordinate system refers to UTM-34. (b) Longitudinal cross section along nearly the thalweg of the Gulf, where the vertical structured grid is shown

\subsubsection{Boundary and initial conditions}

The computational boundary consists of the solid boundary (solid bottom and the coasts) and two open boundaries, located at the Oxeia island-Bay of Killini line, in the west, and at the Mornos - Drepanon pass, in the east. These boundaries have been denoted as OB1 and OB2, respectively (see Fig. 1 in Fourniotis and Horsch, 2015).

Concerning the boundary conditions, all solid boundaries are treated as impermeable, no slip boundaries, where the term no slip should be interpreted, in the context of the $k$ $\varepsilon$ model, in terms of the logarithmic wall functions. In the present work, where we examine exclusively wind-induced flow, it would have been sufficient to fix the height of the free surface at the open boundaries, i.e. OB1 and OB2, had its position been known ahead of the simulations (e.g. by measurements). This is of course not so, and, as an approximation, the free surface is kept fix at the mean sea level. For this procedure to work at all, the depth at the open boundary locations has to be large enough. Thus, the domain of interest was widened by including parts of the adjacent seas, up to a point where the depth of the region proved sufficient (Fourniotis and Horsch, 2010). This technique is also compatible with the desire to calculate as accurately as possible the exchange flowrates which develop with the adjacent seas, i.e the Ionian Sea at the West and the Gulf of Corinth at the East. In our case, this procedure required the additional adjustment by increasing somewhat the depth at the Ionian Sea boundary (OB1), from approximately 80 to $120 \mathrm{~m}$ at the outer part of the computational domain. With these arrangements, the numerical procedure proved quite robust, and no cases of divergence were encountered. The adequacy of the selected domain for the numerical simulations has been extensively tested and discussed in a previous work
(Fourniotis and Horsch, 2010). The simulations presented herein, covering the early summer circulation in the Gulf, have been performed using the same free surface boundary conditions for both the winter and the summer wind-induced circulation in the Gulf.

The boundary vertical density profiles were set equal to the initial conditions (see next paragraph) and were kept constant during the simulation. Finally, for the turbulence model to function properly, a weak initial turbulence level had to be imposed. The turbulence kinetic energy, $k$, and the turbulence dissipation rate, $\varepsilon$, were set to such initial values that the corresponding viscosity coefficient $v_{\mathrm{t}}$ be equal to $10^{-4} \mathrm{~m}^{2} \mathrm{~s}^{-1}$. These values were in accordance with measurements (Crawford and Osborn, 1979) in the ocean, under the thermocline where the currents were very weak: $k_{\mathrm{o}}=3.6 \times 10^{-4} \mathrm{~m}^{2} \mathrm{~s}^{-2}$ and $\varepsilon_{\mathrm{o}}=1.7 \times 10^{-8} \mathrm{~m}^{2} \mathrm{~s}^{-3}$.

On the free surface the condition of no heat exchange was imposed. This is because the time scale of the simulations ( four days) is not long enough to allow surface heat transfer to materially modify the already established stratification. Furthermore, the simulations examine the effect of the stratification on the hydrodynamics circulation. The aforementioned assumption is justified a posteriori by the favorable comparison of the simulated surface temperature field with satellite images which can be found in Fourniotis and Horsch, (2015).

Concerning the initial conditions, all simulations, unless they constituted a continuation of a previous run, were initiated from the state of rest, where the free surface was set equal to the mean sea level. The summer stratification results essentially due to temperature stratification, according to field data (Papailiou, 1982), since in the Papailiou campaign vertical salinity profiles were found to be nearly constant, indicating that the variations in salinity 
are small within the Gulf of Patras (for an instance of winter profile, see also Fig. 2 in Fourniotis and Horsch, 2010). Thus, the initial condition of the stratification used for the simulation of the early summer circulation, was set to be one dimensional (i.e. with no horizontal variations), constructed by averaging five typical vertical temperature profiles and calculating the corresponding density profile. In this calculation the value of the salinity was set, in accordance with the data, equal to 38.5 psu (e.g. Chen

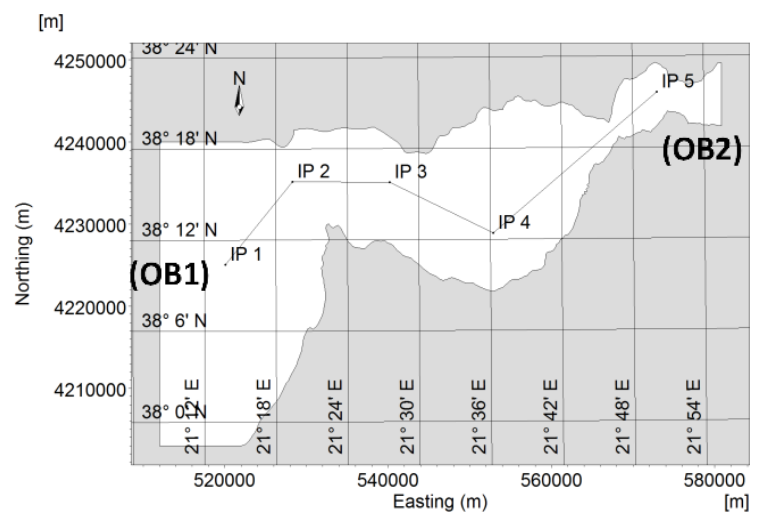

(a) et al., 2005). This mean temperature profile epitomizes the basic thermal stratification characteristics of the early summer regime in the water column of the Gulf, derived from hydrographic observations (Papailiou, 1982), and is the same used in Fourniotis and Horsch, (2015). In Fig. 2, a longitudinal cross section along nearly the thalweg of the Gulf, is given, as has been formatted by the model, applying the mean vertical temperature profile.

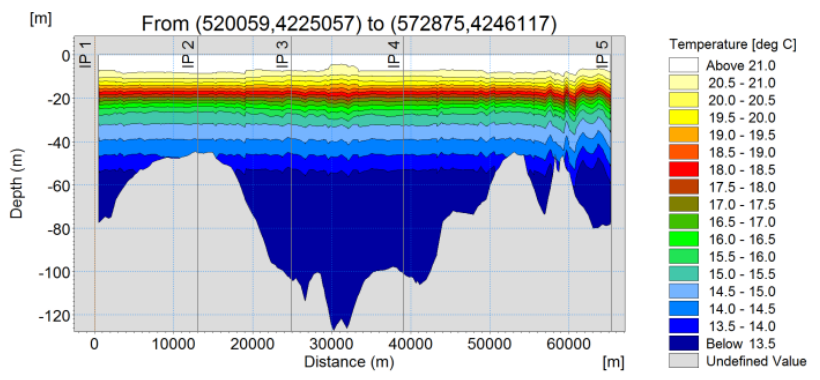

(b)

Figure 2. (a) Plan view of the Gulf of Patras where the longitudinal cross-section has been marked with a polyline, as IP1, IP2, IP3, IP4, IP5, (b) Longitudinal cross section along nearly the thalweg of the Gulf formatted by the model, applying the mean vertical temperature profile

\section{Results and discussions}

\subsection{Objectives of the simulations}

In the present section three dimensional numerical simulations are used to shed light into the structure of the thermal stratification under the effect of a severe SW wind blowing over the Gulf. Our aim is to study the formation of the thermal stratification, i.e. deepening, tilt and erosion of the thermocline under wind forcing, as well as to examine the structure of the baroclinic flow, without taking into consideration the effect of tides. This objective is in view of the absence of adequate field data sets that could be used for verification or fine tuning of the simulations. Further, it has to be noted that during a severe wind event, i.e. a storm event, conditions are consisted where usually field data are lacking. Thus, instead of producing results that would include all complicating factors but could not verified, we prefer to focus on the effect of the purely wind induced flow in the structure and formation of the thermal stratification in the Gulf. Besides, as has been discussed in Fourniotis and Horsch (2010), during neap tides, even moderately strong winds may drive a flow considerably stronger than this weak tidal flow. However, tidal forcing is the major component of the flow in the Gulf, during spring tides or under weak wind forcing. Therefore, the study of the purely wind-induced flow is the first step in understanding the effect of wind on the stratification of the Gulf.

All the simulations, where the flow was driven by a constant wind velocity, were pursued up to the achievement of the steady state or a quasi-steady state, in spite the fact that, in reality, such a state is seldom approached (however, it should be noted, that, according to Piper et al., (1982), at least ENE strong winds may last for days). In this work the effect of a severe southwesterly (SW) wind of $15 \mathrm{~m} / \mathrm{s}$ on the flow hydrodynamics as well as the deepening and erosion of the thermocline in the Gulf is studied, under the condition of the early summer stratification. In order to have a comprehensive understanding of the wind effect on flow structure in the presence of stratification, numerical results are juxtaposed with the corresponding ones of the barotropic circulation, under the same severe wind conditions.

It is noteworthy, however, that the effect of such a severe wind event has been referred, defining the initiation of the winter period in the Gulf, where stirring of waters, destruction of stratification and well mixed conditions were found to occur. More specifically, in Papailiou, (1982) study a storm event is referred occurring at the middle of November 1981, i.e., from November 5-17, where still summer conditions dominated in the Gulf. The effect of those severe wind conditions caused fully well mixed conditions in the water column leading gradually to the uniform density structure which characterizes the thermal structure of the winter months. Having in mind this event, in the current work an attempt to revive those conditions was made by applying a severe wind event on thermal stratification of the Gulf. 


\subsection{Vertical structure of the flow}

In the simulations presented below the shear stress exerted by the wind on the free surface is assumed to be constant both in space and in time. The wind stress produces turbulent kinetic energy which is generated at the free surface and is gradually advected to the deeper parts of the water body. The presence of the thermocline acts as a barrier zone preventing the turbulent diffusion towards the hypolimnion, at least for moderate winds. The strength of the wind as well as the resulting turbulence intensity gradually leads to deepening and erosion of the thermocline.

Based on the numerical simulations, the vertical structure of the wind induced flow, (i.e. flow currents, formation of thermal stratification as well as turbulence characteristics formatted during the wind action) is merely described as follows: At the initiation of wind, the surface waters move in the direction of the wind. The epilimnion works autonomously and the circulation seems to be restricted to the surface well mixed layer, leaving nearly unaffected the subsurface hypolimnetic waters which remain isolated and undisturbed. Continuing the wind action, a general circulation pattern dominates affecting the whole structure of the water column where two circulation regimes are revealed. At the upper well mixed layer, above the thermocline, the directions of currents are dictated by the wind action. Beneath the thermocline, at least at the central part of the Gulf, a counter-rotating circulation cell is formed where its sense of rotation is dictated by the wind action. This circulation pattern seems to be reversed some hours later, under the effect of the severe wind event, concerning mostly the western part of the water body.

Under these conditions the thermocline is eroded and the well mixed surface layer occupies greater part of the water body in the vertical. In Fig. 3 the vertical structure of thermal stratification is given nearly at the center of the Gulf. It is shown that as the severe wind action goes on, the mixed surface layer becomes deeper, and the mean, surface temperature decreases. Based on the numerical simulations it is concluded that four days after the initiation of the sever wind event a quasi-stable stratification occurs, where the thermocline has been established in a new mean depth of $\sim 60 \mathrm{~m}$. The deepening of the thermocline leads gradually to a thick surface layer with nearly uniform density and lower mean temperature. Under these conditions the thermocline is tilted towards the opposite direction of the free surface (Fig. 4), (e.g. Fischer et al., 1979, p. 180). It is noteworthy that the free surface elevation, increases to the wind direction with an exception at the Rio-Antirio straits (Fig. 4a - curve drop between IP4 and IP5). Along the straits the wind-driven flow presents a free surface drop, resembling the one observed when a gravity-driven, open-channel, subcritical flow passes through a constricted cross section. This response was predicted in the Rio-Antirio straits, for the wind-driven flow, where both the depth and the width are restricted (Fourniotis and Horsch, 2010).

In Fig. 5 characteristic time-lapses of the model results are given, where the sequence of temporal progression of the tilt and erosion phenomenon of the thermocline at the end of each simulated day is revealed.

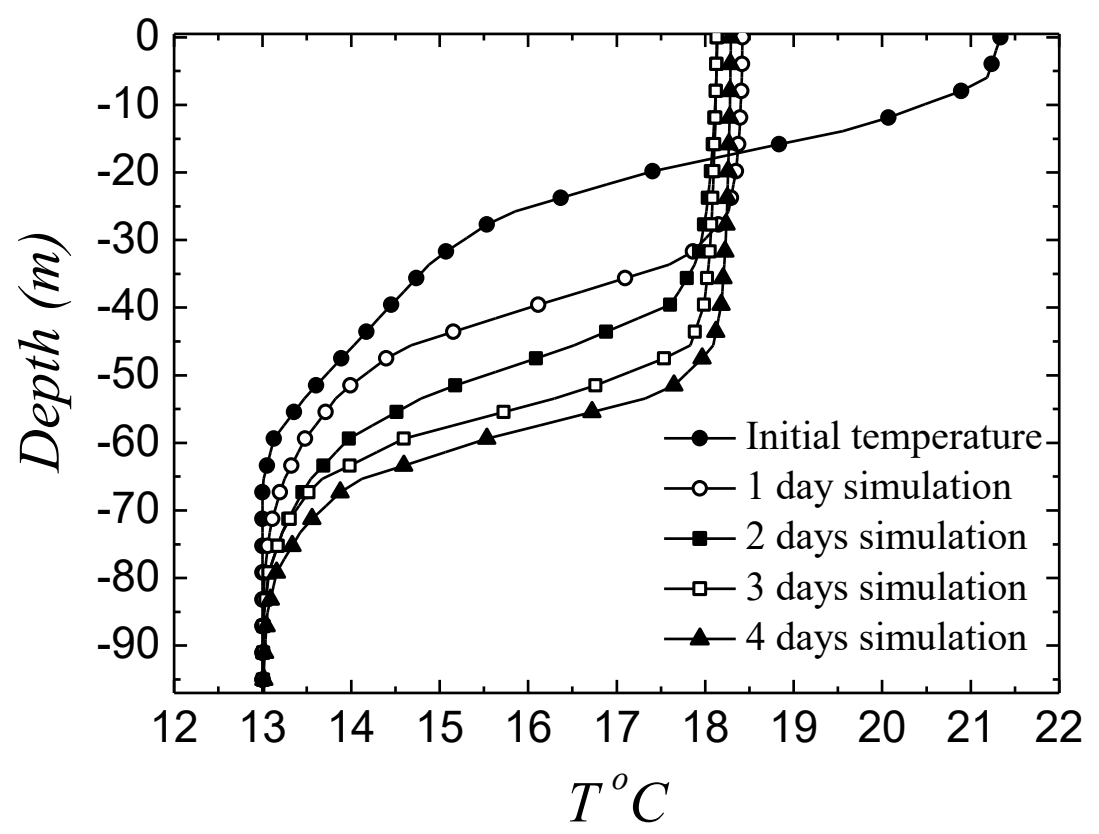

Figure 3. Evolution of vertical temperature profiles formatted during the simulation, under the effect of the $15 \mathrm{~m} / \mathrm{s}$ wind 


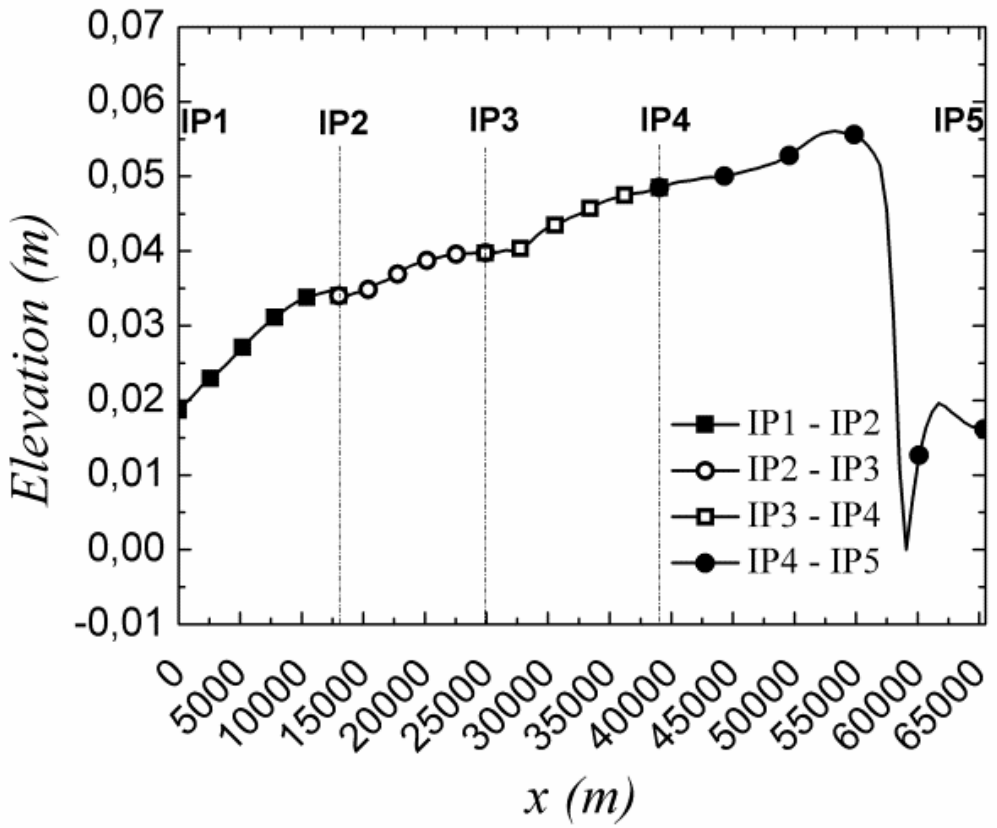

(a)

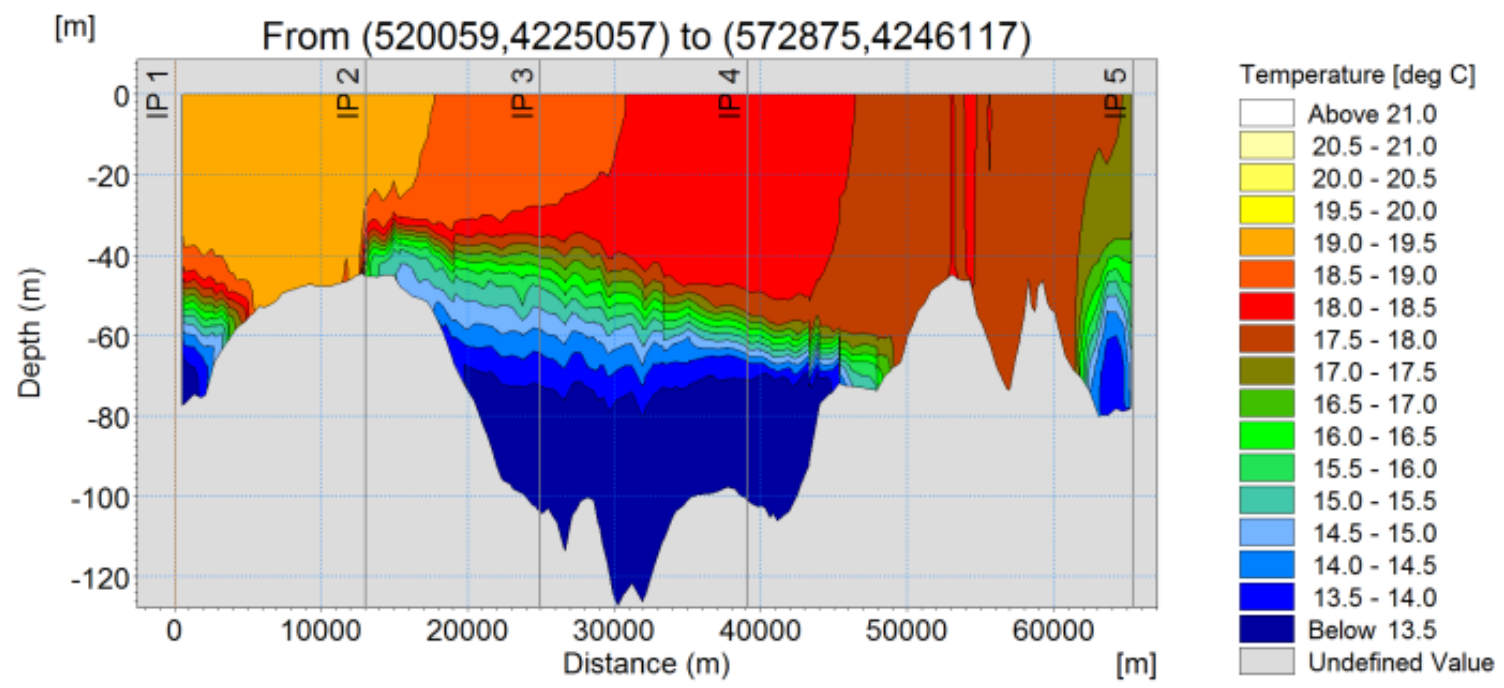

(b)

Figure 4. (a) Calculated free surface elevation due to $15 \mathrm{~m} / \mathrm{s}$ SW wind and (b) Longitudinal cross section along nearly the thalweg of the Gulf, i.e. IP1-IP5, both formatted during the fourth day of the simulation, where tilt and erosion occurs

After the deepening of the thermocline and the formation of a well-mixed surface layer which covers a depth of approximately $50 \mathrm{~m}$, the effect of moderate to medium winds leads to a flow structure which resembles that of the winter, barotropic flow. Specifically, for a moderate wind, i.e. $6 \mathrm{~m} / \mathrm{s}$, which is a characteristic magnitude for the prevailing winds act on the Gulf during the summer months, the development depth of the turbulent eddy viscosity $\left(v_{t}\right)$ in the vertical was calculated to be generated at the upper $20 \mathrm{~m}$ of the well mixed layer of the epilimnion. Under these conditions the flow is considered to be purely geophysical, since the thickness of the upper uniform, well mixed layer, is greater than the resulting structure of the eddy viscosity, which is characteristic for an Ekman layer.
In this case an Ekman spiral grows, the presence of the thermocline notwithstanding. On the contrary, for stronger winds, i.e. the severe SW wind of $15 \mathrm{~m} / \mathrm{s}$, where the parabolic-like structure of the turbulent eddy viscosity covers nearly the whole surface well mixed layer, (above the thermocline), the mode of the flow is shifting towards open-channel type of flow, where a parabolic like viscosity structure occurs (Fig. 6).

\subsection{Horizontal structure of the flow}

The wind-induced currents at the surface layer were calculated to be similar of these that develop in homogeneous waters in the winter, i.e., barotropic circulation, for the same wind conditions (Fig. 7a, b). 

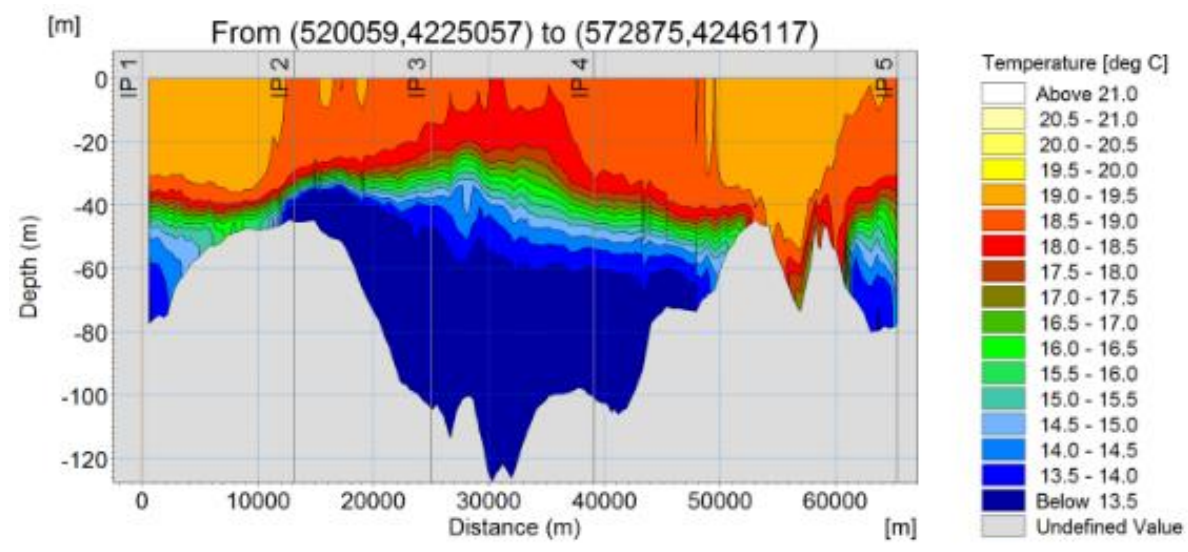

(a)
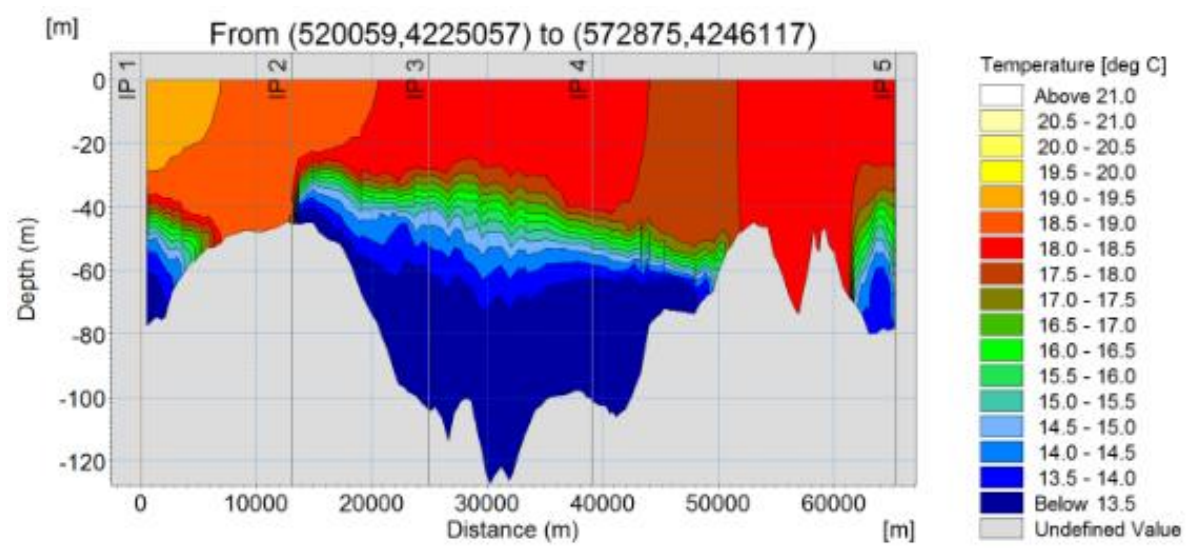

(b)
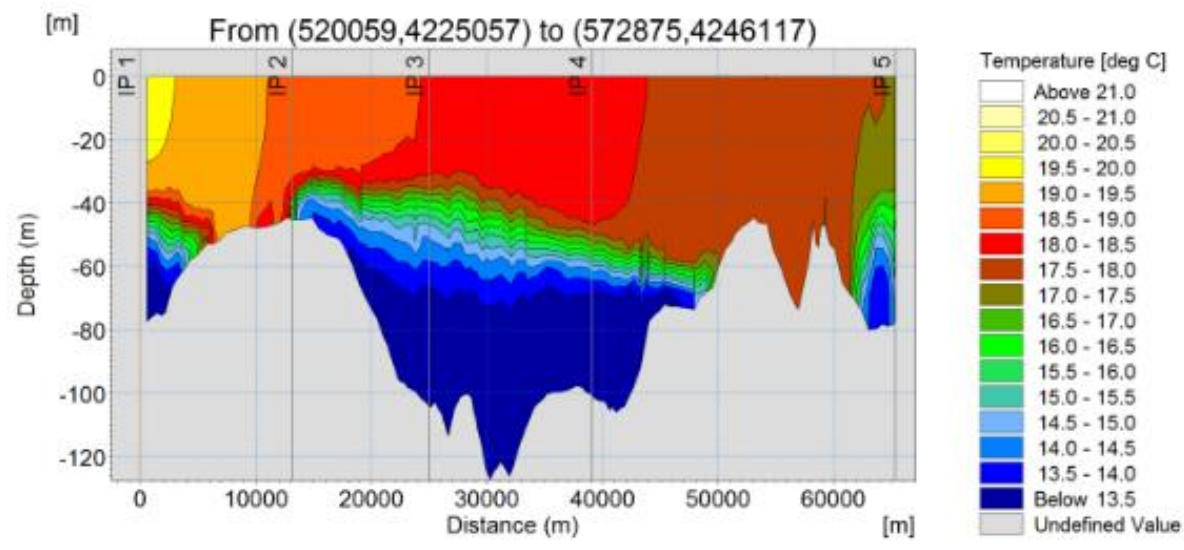

(c)

Figure 5. Characteristic time-lapses where the temporal progression of the tilt and erosion phenomenon of the thermocline, at the end of (a) $1^{\text {st }},\left(\right.$ b) $2^{\text {nd }}$ and (c) $3^{\text {rd }}$ day of the simulation is revealed 


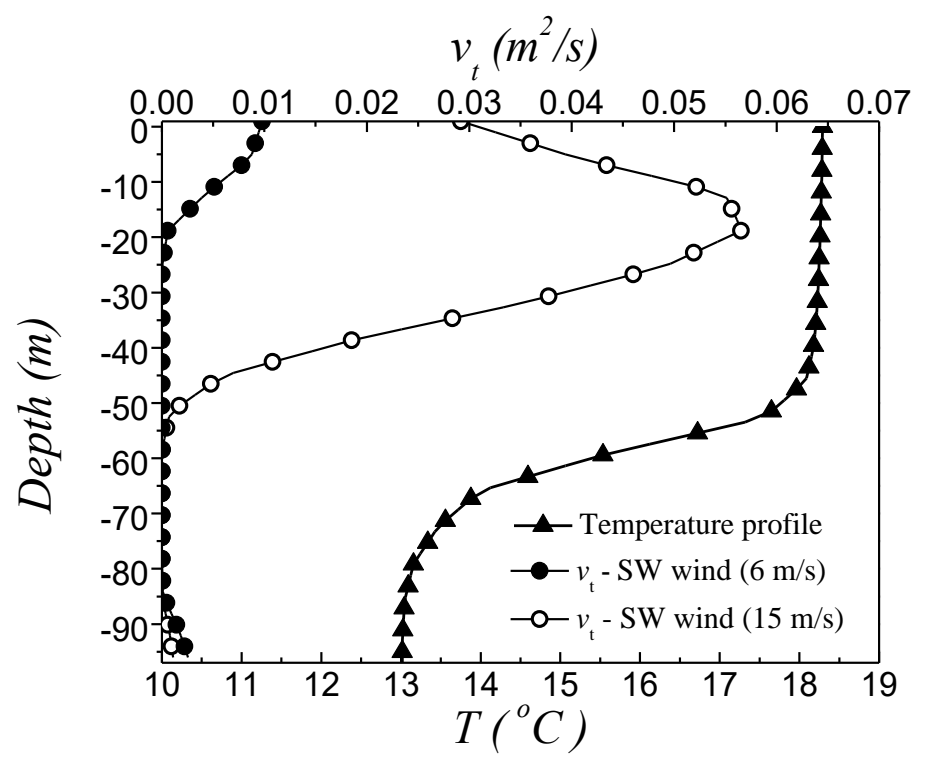

Figure 6. Vertical structure of turbulent viscosity for different wind velocities, after the erosion and deepening of the thermocline

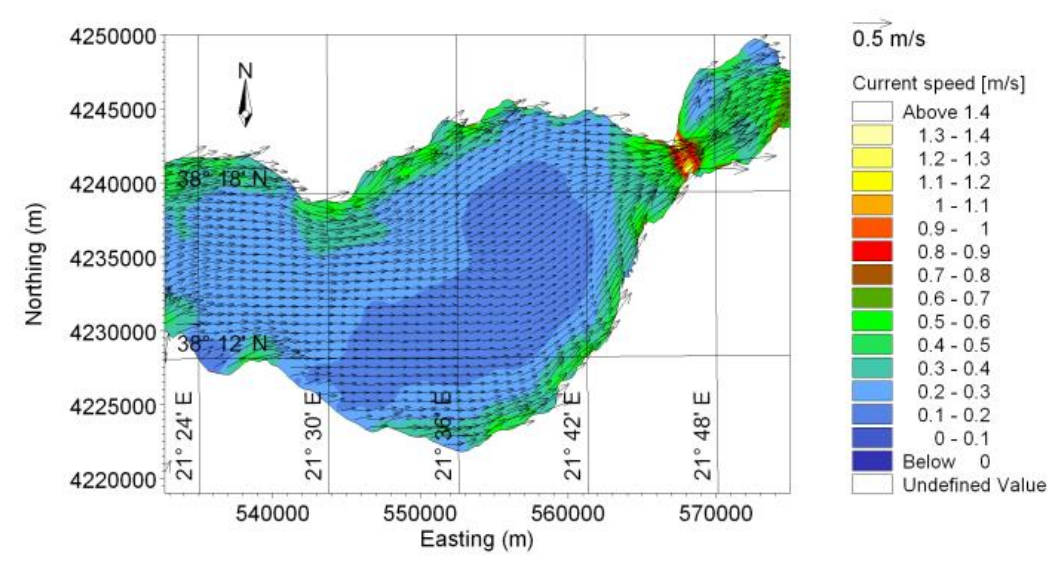

(a)

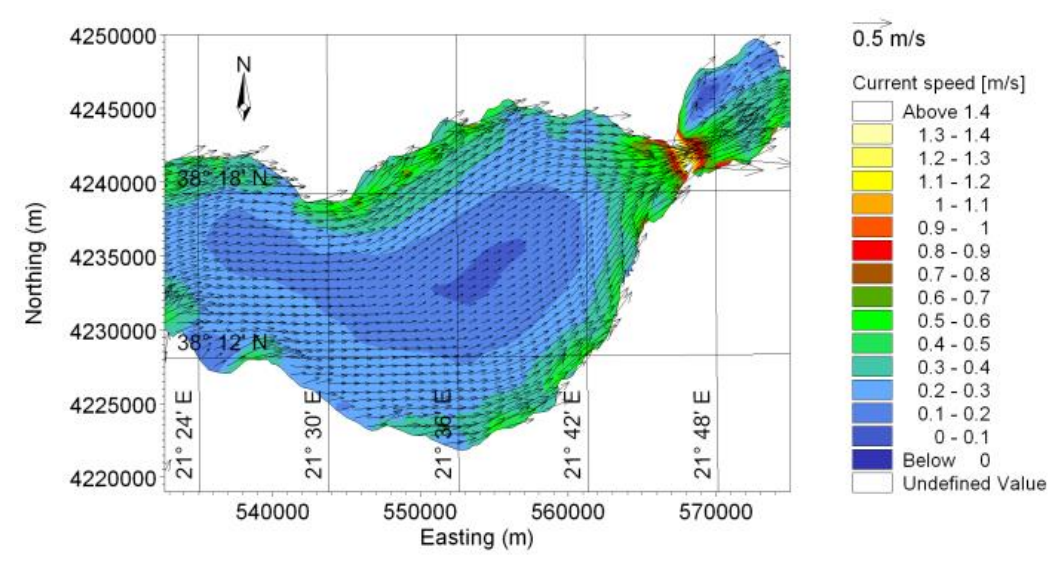

(b)

Figure 7. Surface currents induced by a $15 \mathrm{~m} / \mathrm{s} \mathrm{SW}$ wind $\left(225^{\circ}\right)$, for (a) the summer and (b) the winter regime

This is because in areas where the total depth is larger than the depth of the sills (i.e. at the central part of the Gulf) the deepening of the thermocline at approximately $50 \mathrm{~m}$ leads to a mode of flow which is shifting towards that of the wind-induced barotropic flow (Fourniotis and Horsch, 2010). In the barotropic flow case it was shown that the presence of the sills at both ends of the Gulf, seem to preclude any substantial renewal of bottom waters $1<60$ 
m), which recirculate, being trapped and nearly isolated between the two sills, leaving the wind-induced flow to dominates nearly above the sills, for depths lower than 50$60 \mathrm{~m}$. Similarly, in the near shore waters or shallow waters, the effect of the severe wind leads to well mixed conditions in the vertical and the effect of stratification on the resulting wind-induced currents is negligible.

\subsection{Exchange flowrate at the Rio-Antirio straits}

The evolution of the exchange flowrate at the Rio-Antirio straits, for the wind of $15 \mathrm{~m} / \mathrm{s}$ up to a quasi-steady state, is shown in Fig. 8. It can be noticed that for the wind-induced barotropic circulation, steady state is achieved essentially within one day. In contrast, for the baroclinic circulation under the same wind conditions, the evolution of the exchange flowrate shows some periodicity, due to the development of an internal wave at the Rio-Antirio straits (Fourniotis and Horsch, 2015). The internal wave is initiated approximately $12 \mathrm{~h}$ after the wind stress is applied, as revealed by the numerical simulations, and this caused subsurface inflow from the Gulf of Corinth to the Gulf of Patras, while in the surface layer the current's direction is towards the Gulf of Corinth as dictated by the SW wind. It is noteworthy that the resulting exchange flowrate was calculated to be nearly $20 \%$ lower than the one of the barotropic flow, for the same wind conditions.

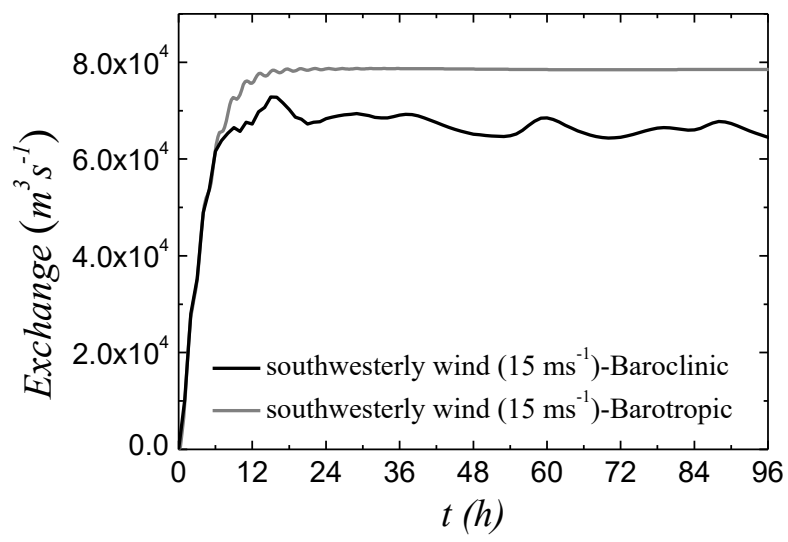

Figure 8. The exchange flowrate between the Gulf of Patras and the Gulf of Corinth. The flow is induced by the $15 \mathrm{~m} / \mathrm{s}$ SW wind

\section{Conclusions}

The wind-induced circulation in the Gulf of Patras, which develops during a severe wind event, has been studied through three-dimensional simulations. The simulations show that under the effect of the wind, deepening, tilt and erosion of the thermocline occurs, which was calculated to be completed nearly during a period of four days. Moreover, the effect of moderate winds on the new thermal stratification, where the thermocline has been established in a new mean depth of approximately $60 \mathrm{~m}$, leads to a barotropic - like flow, notwithstanding, the presence of the deep thermocline. In this case a vertical eddy viscosity structure is calculated which is characteristic of the Ekman layer. The resulting exchange flowrate at the Rio-Antirio straits seems to be affected by the development of an internal wave and was calculated to be nearly $20 \%$ lower than the one of the barotropic flow, for the same wind conditions.

\section{Acknowledgements}

The author would like to acknowledge the help given by the late professor D.D. Papailiou who provided a copy of the unpublished report Papailiou (1982). Useful discussions with Prof. G.M. Horsch are also gratefully acknowledged. Last but not least author addresses special thanks to Miss P.D. Askouni for the text editing.

This paper is part of the 03ED617 research project, implemented within the framework of the "Reinforcement Programme of Human Research Manpower" (PENED) and co-financed by National and Community Funds (25\% from the Greek Ministry of Development-General Secretariat of Research and Technology and 75\% from E.U.-European Social Fund).

\section{References}

Antonopoulos J., Grigoropoulos S., Tsonis S. and Yannopoulos P. (1992), (a). Research investigation of physical-chemical parameters of seawater and its biological pollution potential on underwater construction in the area of Rio-Antirio for the bridge project. Final Report: 1. Physical-chemical parameters of seawater, Ministry of Environment, Physical Planing and Public Works-Directorate D1. University of Patras, Dept. of Civil Engineering (in Greek).

Bates B., Kundzewics Z.W., Wu S. and Palutikof J. (2008), Climate Change and Water. Technical Paper of the Intergovernmental Panel on Climate Change. IPCC Secretariat, Geneva, Switzerland, pp. 210.

Cataudella S., Crosetti D., Massa F. (eds) (2015), Mediterranean coastal lagoons: Sustainable management and interactions among aquaculture, capture fisheries and the environment, Studies and Reviews No. 95, General Fisheries Commission for the Mediterranean, Food and Agriculture Organization of the United Nations (FAO), Rome, 2015, 278 p.

Chen M., Murali K., Khoo B.-C., Lou J. and Kumar K. (2005), Circulation Modelling in the Strait of Singapore, Journal of Coastal Research, 21(5), 960-972.

Coma R., Ribes M., Serrano E., Jiménez E., Salat J. and Pascual J. (2009), Global warming-enhanced stratification and mass mortality events in the Mediterranean, PNAS, Proceedings of the National Academy of Sciences of the United States of America, 106(15), 6176-6181.

Crawford W.R. and Osborn T.R. (1979), Energetics of the Atlantic equatorial currents, Deep-Sea Research, 26 (Suppl. II), 309324.

DHI 2007. MIKE 3 FLOW MODEL FM. Hydrodynamic module-User Guide. DHI, Software.

Fischer H.B., List E.J., Koh R.C.Y., Imberger J. and Brooks N.H., (1979), Mixing in Inland and Coastal Waters, Academic Press, Inc., $483 \mathrm{p}$.

Fourniotis N.Th. and Horsch G.M. (2007), Validation of a threedimensional hydrodynamic model and application to the Gulf of Patras in Greece, $32^{\text {nd }}$ Congress of IAHR, Harmonizing the Demands of Art and Nature in Hydraulics, Venice, Italy, 1-6 July, SS13-21, Vol. 1, 10 p.

Fourniotis N.Th. and Horsch G.M. (2010), Three-dimensional numerical simulation of wind-induced barotropic circulation in the Gulf of Patras, Ocean Engineering, 37(4), 355-364. 
Fourniotis N.Th. and Horsch G.M. (2012), Simulation of the FarField Dilution of Effluents into the Gulf of Patras (Greece), Fresenius Environmental Bulletin, 21(4), 868-879.

Fourniotis N.Th. and Horsch G.M. (2013), The fate of pollution due to a river: A numerical study for south-eastern coasts of the Gulf of Patras (Greece), Fresenius Environmental Bulletin, 22(12), 3448-3457.

Fourniotis N.Th. and Horsch G.M. (2015), Baroclinic Circulation in the Gulf of Patras (Greece), Ocean Engineering, 104, 238-248.

Fourniotis N.Th., 2009. Three-Dimensional Numerical Simulation of the Hydrodynamic Circulation in the Gulf of Patras, with Emphasis on the Currents in the Coastal Zone of the Port of Patras. Ph.D. thesis, Dept. of Civil Engineering, Univ. of Patras, Patras, Greece (in Greek), 323 p.

Friligos N., Theocharis A. and Georgopoulos D. (1985), Preliminary Chemical and Physical Observations During Summer 1980 on a Silled Embayment in the Ionian Sea, Vie Milieu, 35(2), 115125.

Hadjitheodorou C., Antonopoulos J., Lascaratos A., Papageorgiou E. and Trova, E. (1992), Investigation of the sea currents in the area of Rio-Antirio for the bridging project. Final Report, Univ. of Patras, Dept. of Civil Engineering (in Greek).

Horsch G.M. and Fourniotis N.Th. (2017), Wintertime Tidal Hydrodynamics in the Gulf of Patras, Greece, Journal of Coastal Research, 33(6), 1305-1314.

Lascarato, A., Salusti E. and Papageorgaki G. (1989), Wind-induced upwellings and currents in the gulfs of Patras, Nafpaktos and Korinthos, Western Greece, Oceanologica Acta, 12(3), 159164.

Modiri-Gharehveran M., Etemad-Shahidi A. and Jabbari E. (2014), Effects of climate change on the thermal regime of a reservoir, Proceedings of the Institution of Civil Engineers - Water Management, 167(10), 601-611.

Papageorgiou E., Balopoulos E., Papadopoulos V. and Charalabakis A. (1987), Current observations in the Eastern Ionian Sea: Patraikos Gulf, $2^{\text {nd }}$ Panhellenic Symposium of Oceanography and Fisheries, HCMR, Athens 11-15 May, 242253.

Papailiou D.D. (1982), Oceanographical study in Patras Gulf waters for pollution management - Vol. II. University of Patras, Dept. of Mechanical Engineering, Patras, Greece (in Greek).

Piper D.J.W., Panagos A.G., Kontopoulos N. and Spiliotopoulou M. (1982), Coastal processes and morphology, Gulf of Patras, Greece, Zeitschrift fuer Geomorphologie N.F, 26(3), 365-374. 